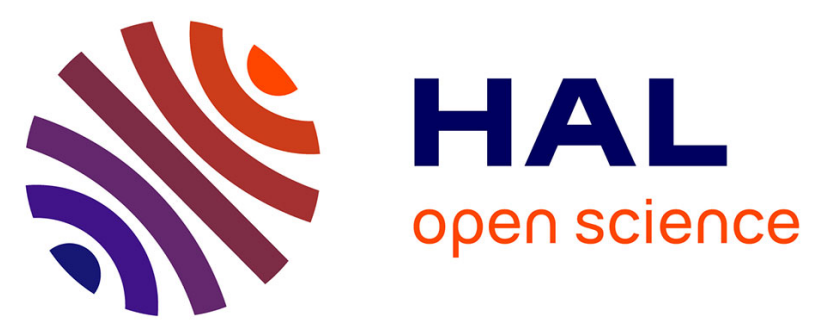

\title{
Electrochemical quenching of the fluorescence produced by NBD-labelled cell penetrating peptides: A contribution to the study of their internalization in large unilamellar vesicles
}

Raquel de Oliveira, Mathieu Durand, Lylian Challier, Pierluca Messina, Jean Marie Swiecicki, Margherita Di Pisa, Gérard Chassaing, Solange Lavielle, Olivier Buriez, Eric Labbé

\section{- To cite this version:}

Raquel de Oliveira, Mathieu Durand, Lylian Challier, Pierluca Messina, Jean Marie Swiecicki, et al.. Electrochemical quenching of the fluorescence produced by NBD-labelled cell penetrating peptides: A contribution to the study of their internalization in large unilamellar vesicles. Journal of Electroanalytical Chemistry, 2017, 788, pp.225-231. 10.1016/j.jelechem.2017.02.006 . hal-01469377

\section{HAL Id: hal-01469377 \\ https: / hal.sorbonne-universite.fr/hal-01469377}

Submitted on 16 Feb 2017

HAL is a multi-disciplinary open access archive for the deposit and dissemination of scientific research documents, whether they are published or not. The documents may come from teaching and research institutions in France or abroad, or from public or private research centers.
L'archive ouverte pluridisciplinaire HAL, est destinée au dépôt et à la diffusion de documents scientifiques de niveau recherche, publiés ou non, émanant des établissements d'enseignement et de recherche français ou étrangers, des laboratoires publics ou privés. 


\title{
Electrochemical Quenching of the Fluorescence produced by NBD-labelled Cell Penetrating Peptides: a contribution to the study of their internalization in Large Unilamellar Vesicles
}

\author{
Raquel de Oliveira $^{a}$, Mathieu Durand ${ }^{a}$, Lylian Challier ${ }^{a}$, Pierluca Messina ${ }^{a}$, Jean Marie Swiecicki ${ }^{b}$, \\ Margherita di Pisa ${ }^{b}$, Gérard Chassaing ${ }^{b}$, Solange Lavielle ${ }^{b}$, Olivier Buriez $^{a}$ and Eric Labbé ${ }^{a}$, \\ a Ecole Normale Supérieure - PSL Research University, Département de Chimie, Sorbonne \\ Universités - UPMC Univ. Paris 06, CNRS UMR 8640 PASTEUR, 24 rue Lhomond, 75005 Paris, \\ France \\ ${ }^{b}$ Ecole Normale Supérieure - PSL Research University, Département de Chimie, Sorbonne \\ Universités - UPMC Univ. Paris 06, LBM, 4, Place Jussieu, 75005 Paris, France
}

\begin{abstract}
:
This work investigates the implementation of a simple and versatile electrochemical setup aimed at achieving a fast and complete fluorescence extinction of NBD-labelled (NBD = 7-nitrobenz-2-oxa1,3-diazole) cell penetrating peptides contained in 2-5 $\mathrm{cm}^{3}$ samples containing phosphate buffer + Large Unilamellar Vesicles. The quenching is obtained through a reductive electrolysis in a 2compartment cell homebuilt from disposable plastic labware, which remains inert towards the adsorption of both peptides and lipid vesicles. Considering the micromolar concentration of NBDtagged peptides, the main electrochemical reaction observed is hydrogen evolution, NBD reduction representing a small fraction of the cathodic current/charge engaged. The electrolysis conditions are discussed with respect to the nature of the reduction products formed, the integrity of Large Unilamellar Vesicles and phosphate buffering properties. This electrochemical method is compared to the traditional chemical dithionite quenching of NBD and tested to monitor the internalization of Cell Penetrating Peptides in Large Unilamellar Vesicles.
\end{abstract}

Keywords: fluorescence quenching, eElectrochemical, cell penetrating peptides, internalization, Large Unilamellar Vesicles

\section{Introduction}

The transport of molecules across biological membranes [1] is a crucial issue in drug delivery, signal transduction and peptide/protein internalization. Cell-penetrating peptides (CPPs), namely, act as vectors for a variety of cargoes such as nucleotides, proteins, nanoparticles or therapeutic agents [2-6]. The uptake of these peptides - which are mostly cationic under physiological pH conditions - within cells or liposomes delimited by phospholipid bilayers has risen a number of questions about the postulated energy- 
independent internalization mechanism (also called passive transport) of charged peptides across hydrophobic barriers $[4,7]$.

In this context, fluorescence methods have been intensively used to monitor and quantify the amount of internalized peptides within liposomes during a given incubation period vis-à-vis those located outside [811].

NBD (7-nitrobenz-2-oxa-1,3-diazole) is a small fluorescent probe originally introduced to label proteins through binding to their hydrophobic regions [12]. The poor steric hindrance of NBD, making this fluorescent probe structurally neutral upon covalent grafting has popularized its use in the labelling of phospholipids $[13,14]$, sugars [15] or CPPs $[10,16]$.<smiles>O=[N+]([O-])c1cccc2nonc12</smiles>

Chemical structure of NBD

In the study of CPP internalization within cells or vesicles, the quantification of internalised peptides relies on the comparison between fluorescence emitted before incubation and after incubation + chemical quenching of the fluorescence emitted by non-internalised peptides, as depicted in scheme 1 :

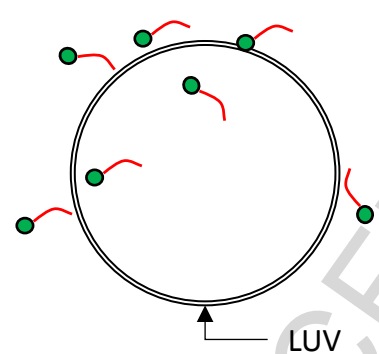

1) incubation

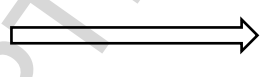

2) quenching

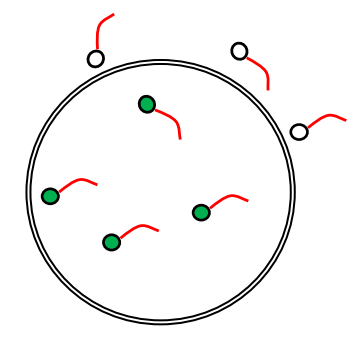

o NBD-CPP

of quenched NBD-CPP

\section{Scheme 1}

\section{Classical DT quenching procedure used to monitor CPP internalization}

This procedure is convenient as long as the cell or the vesicle remains hermetic to the agent used to switch fluorescence off after the incubation period. The quenching of NBD fluorescence is generally carried out through the introduction of reducing agents such as hydrogen sulphide [17] and more traditionally dithionite $[18,19]$, the latter being also described for its fluorescence quenching properties of chlorophyll [20]. However, this cheap, physiologically compatible chemical quencher has recently been found to permeate $\mathrm{POPC} /$ cholesterol vesicles $(\mathrm{POPC}=1$-Palmitoyl-2-oleoylphosphatidylcholine $)$, the permeation relative rate of dithionite vs. a model NBD-labelled phospholipid (NBD-DMPE, DMPE $=$ 1,2-Dimyristoyl-snglycero-3-phosphoethanolamine) being significantly higher in liquid ordered phase than in liquid disordered 
phase [21]. This permeation property could therefore severely affect translocation studies based on middle- to long-term fluorescence monitoring after dithionite quenching, since this questions the postulate that internalized fluorescent probes remain unaffected by quenching agents introduced in the external medium.

These considerations prompted us to develop a non-chemical strategy to quench NBD fluorescence. Considering the redox nature of the reaction between dithionite and NBD, an electrochemical reduction could bring a significant benefit in several aspects[22]: i) It avoids adding exogenous chemical agents like dithionite ii) the heterogeneous nature of electron transfers achieved at solid electrodes imposes that the electrochemical reduction only affects species dissolved outside the vesicles or aggregated in the outer phospholipid leaflet of the vesicles iii) the counter-reaction (oxidation) can be separated in another compartment. Electrochemical activation/deactivation of fluorescent probes is not a new concept per se. Indeed, Miomandre et al. have described the electrochemically controlled switching of chloromethoxytetrazine [23], and other dyes have also been switched on/off electrochemically [24-27].

Herein, we propose an electrochemical method, which allows the quantitative fluorescence extinction of 2$5 \mathrm{~mL}$ samples containing NBD-labelled peptides. Our intention was to allow non-electrochemists to both reproduce the electrochemical setup and achieve quantitative electrochemical quenching routinely. Some specifications had to be considered: the setup was dimensioned in view of follow-up fluorescence measurements; the electrolysis therefore concerned $2-5 \mathrm{~mL}$ volumes of solution. The surface area of the electrodes had to be large enough compared to the volume of the solution to run reasonably fast electrolyses ( $<1 \mathrm{~min}$ ). Vitreous carbon foams have been found to meet this requirement since high specific surface materials $\left(>20 \mathrm{~cm}^{2} / \mathrm{cm}^{3}\right.$ ) can be purchased and carved to the desired shape. Once optimized, we have examined the resulting electrochemical setup in terms of buffer capacity, LUV integrity and finally tested on the quenching of fluorescence emitted by non-internalized NBD-labelled peptides.

\section{Experimental section}

\section{Preparation of symmetric LUVs}

DPPG (1,2-Dipalmitoyl-sn-glycero-3-phosphorylglycerol sodium salt) was purchased from Avanti Polar Lipids, as a solution in chloroform. Depending on the desired LUV composition, the appropriate amount of phospholipids (PLS) was introduced in a round-bottomed flask and chloroform was slowly evaporated under vacuum at $40{ }^{\circ} \mathrm{C}$ using a rotating evaporator and then under high-vacuum during at least $2 \mathrm{~h}$. The lipids were hydrated with phosphate-buffered saline solution $(50 \mathrm{mM})$ at $\mathrm{pH}=7.4$ to a concentration of 1 $\mathrm{mM}$. The turbid suspension of multilamellar vesicles was subsequently extruded 7 times through a $200 \mathrm{~nm}$ polycarbonate track-etch membrane and 10 times through a $100 \mathrm{~nm}$ polycarbonate track-etch membrane (Whatman) using a $10 \mathrm{~mL}$ Thermobarrel extruder (LipexBiomembranes). Since DPPG has a high transition 
temperature $\left(41^{\circ} \mathrm{C}\right)$, the extruder was heated using a thermocontrolled circulation bath. The LUV solutions were used from the day and within two weeks after their preparation.

\section{Fluorescence experiments}

Fluorescence emission spectra were recorded with a Jasco Fluorescence Spectrophotometer at $20^{\circ} \mathrm{C}$ controlled by a JASCO MCB-100 mini circulation bath. A xenon lamp was used as the excitation source and both excitation and emission slit widths were set at $5 \mathrm{~nm}$. To avoid peptide adsorption and subsequent fluorescence quenching, polystyrene cuvettes were used instead of glass. During measurements the solutions were stirred at $800 \mathrm{rpm}$.

For the internalization experiments, unlabelled LUVs were used with NBD-labelled CPPs introduced at a concentration of $0.1 \mu \mathrm{M}$. The excitation wavelength was fixed at $460 \mathrm{~nm}$ while the emission was monitored at $555 \mathrm{~nm}$.

\section{Quantification of the internalization into LUVs}

For experiences in the gel phase, peptides $(0.1 \mu \mathrm{M})$ were incubated at $20{ }^{\circ} \mathrm{C}$ for $10 \mathrm{~min}$ with the LUVs (DPPG, $10 \mu \mathrm{M}$ ) in $50 \mathrm{mM}$ PBS $+0.1 \mathrm{mM} \mathrm{HCl}$. The reductions by adding dithionite or by electrochemical methods were performed at the same temperature as well as the quantification of fluorescence.

For experiences in the fluid phase, peptides were incubated at $41^{\circ} \mathrm{C}$ for $10 \mathrm{~min}$ with the LUVs in $50 \mathrm{mM}$ PBS

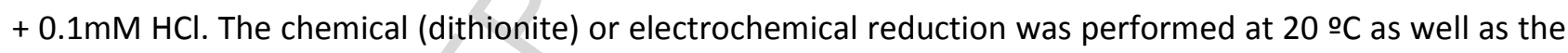
quantification of fluorescence.

\section{Electrochemical measurements}

Voltammetric measurements and both galvanostatic and potentiostatic electrolyses were performed at room temperature using a potentiostat (Autolab type PGSTAT100N, Ecochemie) controlled by GPES 4.9 software.

\section{Cyclic voltammetry}

Cyclic voltammetry was performed using glassy carbon as working electrode. Electrodes ( $1 \mathrm{~mm}$ diameter) were polished to a mirror finish with emery paper of decreasing grain size and alumina powder (Minitech 
233 by PRESI), sonicated for $10 \mathrm{~min}$ in ultrapure water, and dried before use. The reference electrode was a commercial saturated calomel electrode (SCE - Radiometer Analytical).

\section{Electrolysis}

Galvanostatic electrolyses were carried out at -150 mA. All electrolyses were performed in twocompartment homemade cells separated by a porosity 4 glass frit membrane. The cell compartments were made of two $5 \mathrm{~mL}$ syringe barrels capped at the bottom of the tip to avoid leakage. A hole was cut in the extremity of each barrel to introduce a plastic tube with the glass frit membrane of $3 \mathrm{~mm}$ diameter. The region around the plastic tube was externally sealed with araldite (Araldite 2011, Huntsman). The glass frit separator was purchased from Ellipse ${ }^{\circledR}$ at the lowest available diameter to minimize the adsorption of CPPs.

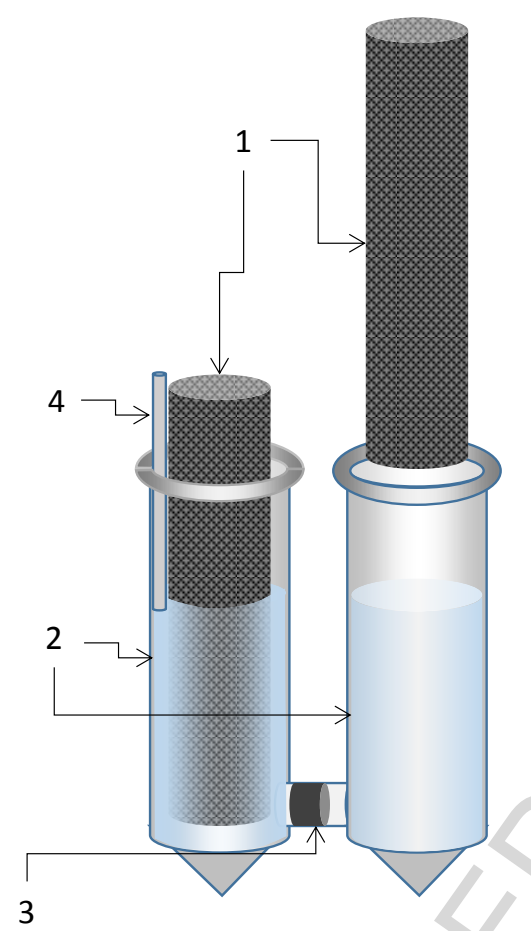

Home-built electrochemical cell used for the electrolyses :

1. vitreous carbon foam electrodes

2. $5 \mathrm{~mL}$ plastic syringe cylinders

3. porosity 4 glass frit separator ( $3 \mathrm{~mm}$ diameter $-2 \mathrm{~mm}$ thickness) inserted in a plastic bridge

4. Plastic cylindrical bridge sealed with agar-agar, filled with aqueous PBS buffer hosting the $\mathrm{Ag} / \mathrm{AgCl}$ wire reference electrode

The working and counter electrodes were made from a vitreous carbon foam (VC003830, Goodfellow). The carbon foam was melded in a shape of a cylinder having almost the same size as the syringe barrel allowing the galvanostatic electrolysis to proceed at current values high enough for fast quenching without imposing too negative potential values. In this way the high electrode surface area allowed performing fast and exhaustive electrolyses. The volume of PBS solutions introduced in each compartment was $3.0 \mathrm{~mL}$.

\section{Fluorescent peptides used in the study}

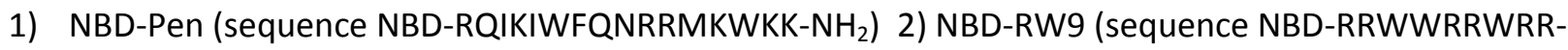
$\mathrm{NH}_{2}$ ), NBD-R9 (sequence NBD-RRRRRRRRR-NH ${ }_{2}$ )

\section{Syntheses - Experimental Procedures}




\section{General procedure for Boc solid-phase peptide synthesis}

Standard Boc-amino acids, MBHA resin $\left(0.54 \mathrm{mmol} . \mathrm{g}^{-1}\right)$, 1-hydroxybenzotriazole (HOBt), dicyclohexylcarbodiimide (DCC) were purchased from Iris Biotech, GmbH or Novabiochem. 4-Chloro-7nitrobenz-2-oxa-1,3-diazole, (NBD-Cl), was obtained from Sigma-Aldrich.

The sequences were synthesized manually on a MBHA Resin Iris BR 1120 (0.54 mmol g-1, $0.2 \mathrm{mmol}$ ) using SPPS Boc-strategy. For the different couplings, activation was accomplished with DCC/HOBt in NMP. Coupling of NBD-Cl on the $\mathrm{N}$-terminus amine was achieved by addition of NBD-Cl $(0.4 \mathrm{mmol})$ and DIEA (1 $\mathrm{mmol})$ in DMF $(2 \mathrm{~mL})$ to the peptidyl-resin $(0.1 \mathrm{mmol})$. The solution was stirred overnight and then rinsed with $\mathrm{DMF}, \mathrm{CH}_{2} \mathrm{Cl}_{2}$ and $\mathrm{MeOH}(5 \mathrm{~mL})$ and the peptidyl-resin was dried under vacuum. Then, the peptide was cleaved from the resin by treatment with $\mathrm{HF}\left(2 \mathrm{~h}, 0^{\circ} \mathrm{C}\right)$ using anisole $(1.5 \mathrm{~mL} / \mathrm{g}$ peptidyl-resin) and methylsulfide $(0.25 \mathrm{~mL} / \mathrm{g}$ peptidyl-resin) as scavengers. The peptide was precipitated in cold diethylether and the scavengers were removed by filtration. The crude peptide was dissolved in a $10 \%$ solution of acetic acid in water and lyophilized before purification.

\section{General purification and peptide characterization}

The peptides were analysed and purified by RP-HPLC using the following solvents: $A=\left(0.1 \%\right.$ TFA in $\left.\mathrm{H}_{2} \mathrm{O}\right)$ and $B(0.1 \%$ TFA in acetonitrile) on a Waters System with detection at 220, $280 \mathrm{~nm}$ and/or $340 \mathrm{~nm}$ for peptides having an NBD-Tag. Analytical RP-HPLC was performed using an Ace 5 C8-300 column (4.6 x 250 $\mathrm{mm}$ ) at a flow rate of $1.0 \mathrm{~mL} \cdot \mathrm{min}^{-1}$. Preparative RP-HPLC was performed using a SymmetryPrep C8 column $\left(7.8 \times 300 \mathrm{~mm}\right.$ ) at a flow rate of $5.0 \mathrm{~mL} \cdot \mathrm{min}^{-1}$ using optimized gradients. Purified peptides, (over 95\% purity), were characterised by Maldi-Tof MS using $\alpha$-cyano-4-hydroxycinnamic acid (HCCA) as the matrix [1].

\section{$\underline{\text { Typical electrolysis experiments }}$}

$2.95 \mathrm{~mL}$ of PBS $50 \mathrm{mM}$ were introduced in each compartment of the electrochemical cell. In the cathodic compartment, the following solutions were successively added : 1) $20 \mu \mathrm{L}$ of aqueous $\mathrm{HCl} 1 \mathrm{M}$ 2) $30 \mu \mathrm{L}$ of a solution of DPPG LUVs (DPPG at $1 \mathrm{mM}$ ) 3) $3 \mu \mathrm{L}$ of a solution of NBD-labelled CPP at $0.1 \mathrm{mM}$ was introduced. The solution was homogenised by pumping up and down the resulting solution 4 times. Then, the electrodes were introduced in each compartment (GC cylinder of $1.2 \mathrm{~cm}$ diameter and ca. $3.5 \mathrm{~cm}$ height immersed). The electrolysis was performed ( $-150 \mathrm{~mA}$ for $20 \mathrm{~s}$ ). After electrolysis, the electrodes were removed from the cell and the solution contained in the cathodic compartment transferred in a fluorescence cuve. 


\section{Results and discussion}

\subsection{Electrochemical behaviour of NBD-Glycine (NBD-G)}

We first used NBD-glycine (NBD-G) as a test-compound to collect information on the electrochemical behaviour of the NBD probe covalently bonded to an amino acid. The cyclic voltammogram recorded in PBS is presented in Figure 1. The residual cathodic current observed at potential values more negative than -1 $\mathrm{V} / \mathrm{SCE}$ is ascribed to the slow electrochemical reduction of water according to:

$$
\mathrm{H}_{2} \mathrm{O}+\mathrm{e}^{-} \rightarrow 1 / 2 \mathrm{H}_{2}+\mathrm{OH}^{-} \text {(1) }
$$

In Figure 1, the sluggish evolution of the cathodic residual current (dashed line) recorded at a glassy carbon electrode (electrode material known for its large proton/water reduction overpotential) is consistent with a slow reduction process. In the presence of NBD-G, a broad, partially reversible reduction wave is observed, overlapping the background current at around $-0.65 \mathrm{~V}$. Since glycine alone does not show any faradaic process in the potential window explored, this wave accounts for the electrochemical reduction of the NBD probe.

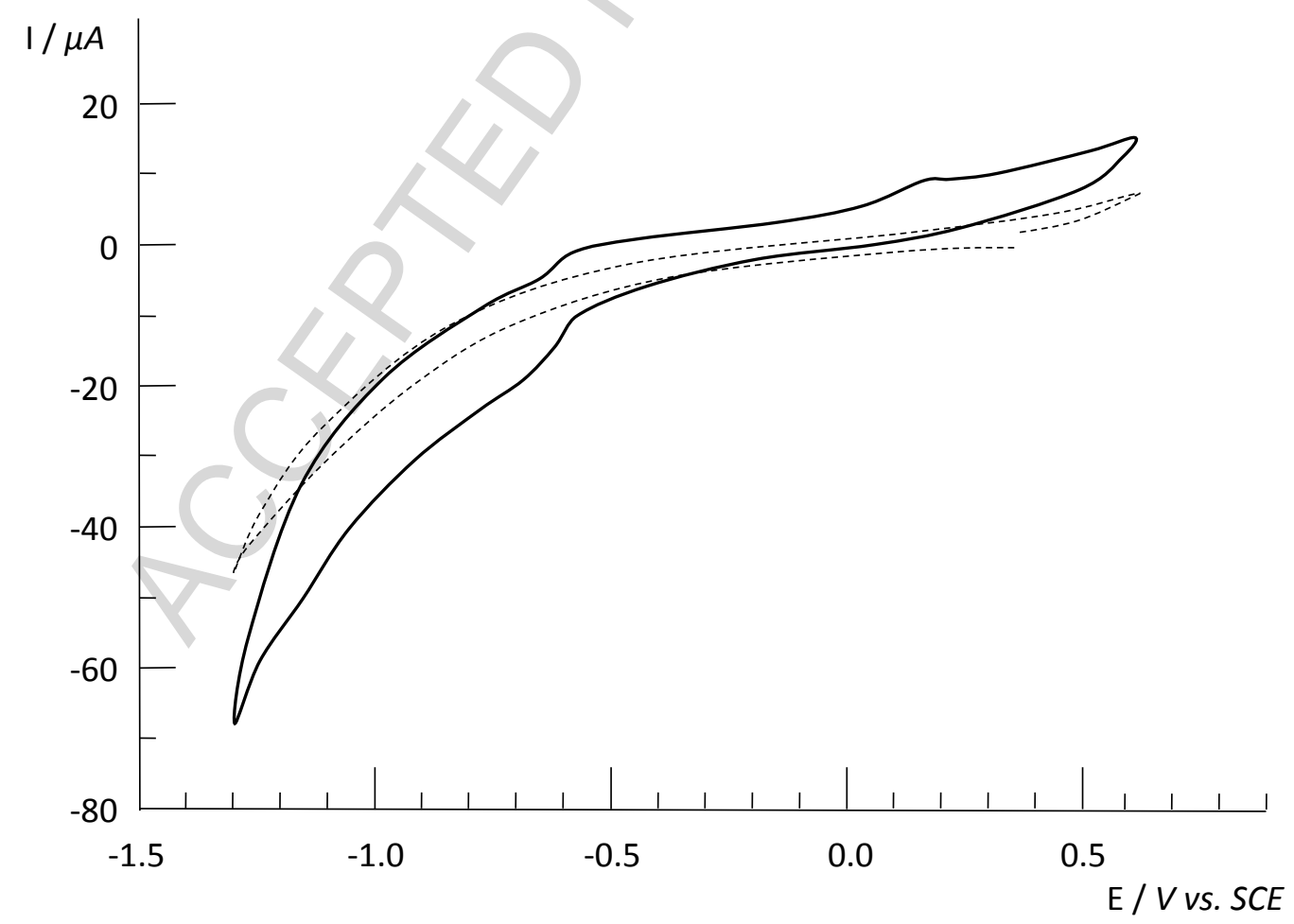

Figure 1

CV of NBD-G at a $1 \mathrm{~mm}$ diameter GC electrode in PBS aqueous buffer (50 mmol. $\left.\mathrm{L}^{-1}\right)$. Dashed line: background CV before addition of NBD-G. Solid line: NBD-G $4 \mathrm{mmol} . \mathrm{L}^{-1}$. Scan rate: $0.1 \mathrm{~V} . \mathrm{s}^{-1}$ 
The electrochemical reduction of aliphatic and aromatic nitro compounds has been extensively reviewed $[28,29]$. The reduction may engage up to 6 electrons to yield the parent amino compound. Actually, in water and more generally in protic solvents the cyclic voltammograms display two successive reduction steps, the first one producing an hydroxylamino intermediate:

$\mathrm{Ar}-\mathrm{NO}_{2}+4 \mathrm{e}^{-}+4 \mathrm{H}^{+} \rightarrow \mathrm{Ar}-\mathrm{NHOH}+\mathrm{H}_{2} \mathrm{O}$

This reduction step is observed at potential values, which strongly depend on several factors, namely the $\mathrm{pH}$ of the medium. At neutral $\mathrm{pH}$ values like in Figure 1, reaction (2) is observed at $-0.7 \mathrm{~V} v$ s. SCE [30], i.e. similar to the reduction potential value of NBD-G in Figure 1. Therefore, the wave at $-0.65 \mathrm{~V}$ observed in Figure 1 is coherent with the reduction of the nitro group. Considering the CV of aqueous PBS presented in Figure 1 (dashed line), any electrolysis at potential values more negative than $-0.7 \mathrm{~V}$ would simultaneously reduce both water and NBD-G, featuring the overall (1) + (2) reductions.

\subsection{Optimization of the electrochemical setup used for electrolyses}

We have tested glass electrochemical cells to perform the electrolyses of PBS solutions containing both LUVs and cationic peptides. Using such "classical" cells for electrochemists, a noticeable loss of fluorescence (typically $20-50 \%$ of relative fluorescence) was observed upon introducing the NBD-tagged CPPs in the cell, in the absence of electrolysis. Actually, the adsorption of cationic peptides on glass has been reported [31] and the glass surface area represented by the cell walls and the frit separator may contribute significantly to the adsorption of CPPs. In order to minimize the adsorption of CPPs during the electrolyses, we decided to build an electrochemical cell essentially made of plastic containers. A special focus was made on the accessibility/availability of these cells to non-electrochemists as well as their volume compatibility with the follow-up fluorescence measurements in spectrometric cells of $2-5 \mathrm{~mL}$. The cell finally used is described in the experimental section and features $5 \mathrm{~mL}$ plastic syringes (anodic and cathodic compartments) connected to each other through the smallest commercially available glass frit. Such a cell configuration also facilitated the introduction of cylindrical vitreous carbon foams as electrodes, which allowed the electrolysis of the NBD-labelled peptides to proceed in 20s. Additionally, we have carried out successive electrolyses on LUVs solutions, which had been previously incubated at $41^{\circ} \mathrm{C}$ with RW9-NBD. The fluorescence appeared unchanged by these electrolyses, showing that electrolyses did not affect the integrity of LUVs (considering that most of the fluorescence is emitted by NBD located in the hydrophobic region of the LUV lipidic bilayer). 
We have carried out several electrolyses in single compartment cells, using different electrode materials (platinum, gold, carbon). Unfortunately, those electrolyses led to anode passivation and sometimes to turbid solutions in the presence of LUVs. Moreover, the possible generation of hydroxyl radicals at the anode, which are known intermediates in the electrochemical oxidation of water [32], may oxidize lipids in the LUVs [33], making single compartment electrolyses too aggressive with respect to the integrity of LUVs. In this context, we decided to perform the electrolyses in compartmented electrochemical cells from 50 mM PBS solutions.

\subsection{Electrochemical quenching of the fluorescence emitted by NBD-G}

With this respect, the electrochemical reduction of NBD-G was carried out using the homemade 2compartement cells described in the experimental section. Stepwise galvanostatic electrolyses of $0.3 \mathrm{C}$ were performed and the relative fluorescence of the solution reported as a function of the total charge passed. The results are reported in Figure 2.

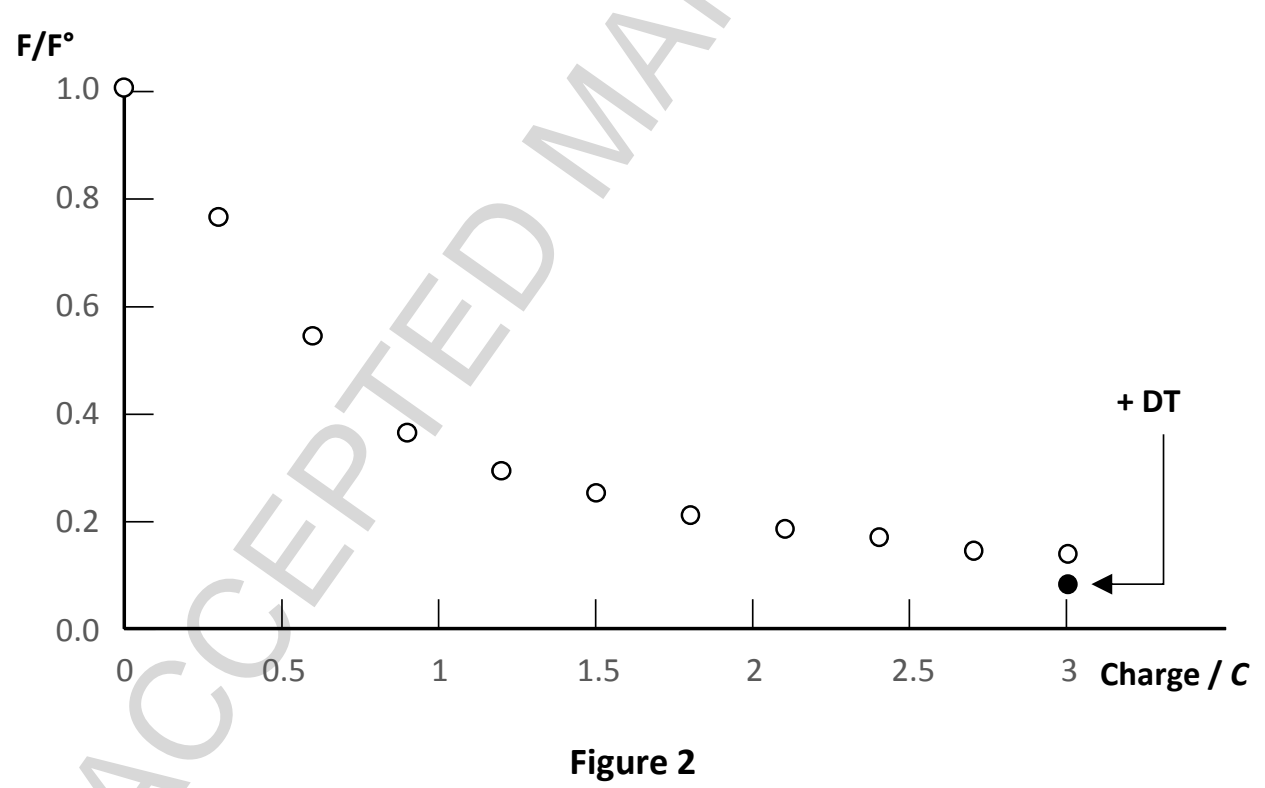

White circles : relative fluorescence intensity recorded as a function of the charge during the $150 \mathrm{~mA}$ galvanostatic reductive electrolysis of a $3 \mathrm{~mL}$ solution of NBD-G $\left(0.5 \mu \mathrm{mol} . \mathrm{L}^{-1}\right)$ in aqueous PBS $\left(50 \mathrm{mmol} . \mathrm{L}^{-1}\right)$. Black circle : relative fluorescence after addition of excess dithionite (DT) to the solution obtained after the ultimate electrolysis (3C).

The evolution presented in Figure 2 unambiguously demonstrates the quenching effect of the electrochemical reduction on the fluorescence emitted by NBD. The cathode potential stabilized at $-1.7 \mathrm{~V}$ vs. SCE, a value more negative than the reduction wave of NBD-G in Figure 1. Moreover, gas bubbles 
escape from the cathode all along the electrolyses. These observations are consistent with the simultaneous reduction of water and NBD from (1) + (2) reactions, as anticipated from the results of cyclic voltammetry. A final addition of a large excess of dithionite (black circle in Fig. 2), introduced to fully quench the remaining fluorescence, revealed that all NBD-G fluorophores had already been reduced after a $3 \mathrm{C}$ electrolysis. Therefore, the quenching of NBD-labelled molecules can be quantitatively achieved through electrolysis, which proceeds fast enough (compared to incubation periods, i.e. 20s at -150 mA with respect to few minutes) to be envisioned in CPP transport studies based on the quenching of non-internalized fluorophores.

\subsection{Buffering capacity of PBS under electrolysis conditions}

The effect of a fast $\mathrm{pH}$ jump on the fluorescence quenching of NBD has been recently described and used to evaluate the intravesicular accumulation of NBD-labelled peptides [10]. A full fluorescence quenching was observed in a 7-11 pH range upon introduction of hydroxyl anions for a NBD labelled cell penetrating peptide. With this respect, the reductive electrolysis carried out in dilute NBD-G solutions feature the coulometric generation of hydroxyl anions according to (1) as the main electrochemical reaction. Such a quantitative production of $\mathrm{HO}^{-}$during the electrolysis could alter the buffer capacity of PBS and subsequently cause a significant $\mathrm{pH}$ increase. In order to discard a quenching of fluorescence only due to the $\mathrm{pH}$ jump during our electrolyses, we decided to focus on the buffer capacity of PBS solutions under electroreductive conditions.

A priori, $\mathrm{PBS}$ solutions are expected to buffer the $\mathrm{pH}$ evolution for a limited release of $\mathrm{H}^{+}$or $\mathrm{OH}^{-}$. In order to evaluate the impact of the electrolysis on the $\mathrm{pH}$ value within the cathodic compartment, we have monitored the $\mathrm{pH}$ during both chemical (with $\mathrm{NaOH}$ ) and coulometric titrations of PBS. The chemical $(\mathrm{NaOH})$ titration was performed to establish the actual $\mathrm{H}_{2} \mathrm{PO}_{4}{ }^{-} / \mathrm{HPO}_{4}{ }^{2-}$ buffer capacity before running the electrolysis, since the PBS tablets used to make the solutions did not explicitly mention these concentrations. The corresponding titration curves are presented in Figure 3. 

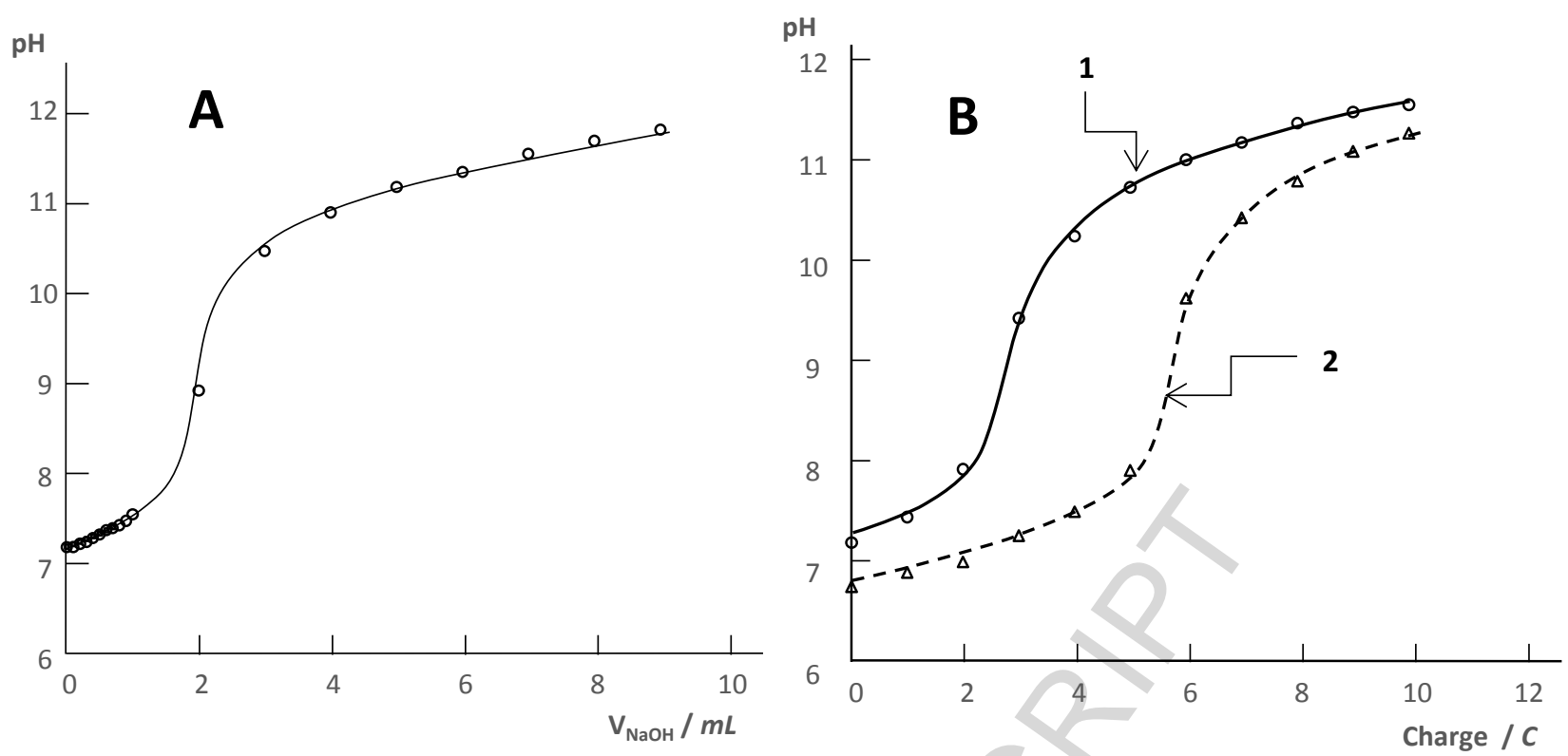

Figure 3

A: Titration of $10 \mathrm{~mL}$ PBS $\left(50 \mathrm{mmol} . \mathrm{L}^{-1}\right)$ by $\mathrm{NaOH} 50 \mathrm{mmol} . \mathrm{L}^{-1}$ - Circles : experimental points. Line: calculated evolution.

B: Intentiostatic electrolysis of $3 \mathrm{~mL}$ of PBS $\left(50 \mathrm{mmol} . \mathrm{L}^{-1}\right.$ ) at a GC foam cathode (150 mA)-

1: experimental (circles) and calculated (solid line) $\mathrm{pH}$ evolution for a quantitative faradaic conversion of $\mathrm{H}_{2} \mathrm{O}$ to $\mathrm{OH}$ from reaction (1) based on the $\mathrm{H}_{2} \mathrm{PO}_{4}^{-} / \mathrm{HPO}_{4}{ }^{2-}$ concentrations estimated from Figure $3 \mathrm{~A}$.

2: experimental (triangles) and calculated (dashed line) $\mathrm{pH}$ evolution during the electrolysis of $3 \mathrm{~mL}$ of a solution composed of PBS $\left(50 \mathrm{mmol}^{-1} \mathrm{~L}^{-1}\right)+20 \mathrm{\mu L}$ of HCl$\left(1 \mathrm{~mol} \cdot \mathrm{L}^{-1}\right)$.

If one assumes that only the electrochemical reaction (1) is taking place in the cathodic compartment, the $\mathrm{pH}$ variation observed in Figure $3 \mathrm{~B}(1)$ fits the calculated "faradaic" titration of the PBS buffer. In our conditions, the quenching of NBD-G appeared complete after 3C (Fig. 2) Therefore, the addition of a small amount $(20 \mu \mathrm{L})$ of a strong acid as in Figure 3B (2) should prevent significant pH evolution during any electrolysis of less than $3 \mathrm{C}$, and would also allow recovering the $\mathrm{pH}$ value of PBS (7.2). In unbuffered solutions, the electrochemical release of hydroxyl anions would dramatically increase the $\mathrm{pH}$ value in the vicinity of the electrode, then possibly triggering an alkaline NBD quenching as discussed earlier in this paragraph [10]. In our conditions, the phosphate buffer and the continuous homogenization caused by the discharge of $\mathrm{H}_{2}$ bubbles make the occurrence of local $\mathrm{pH}$ gradients unlikely. In order to verify that the addition of small amounts of a strong acid had no impact on the electrochemical quenching of NBD-G fluorescence, we have monitored the relative fluorescence of an acidified solution of NBD-G during stepwise electrolyses (Figure 4). 


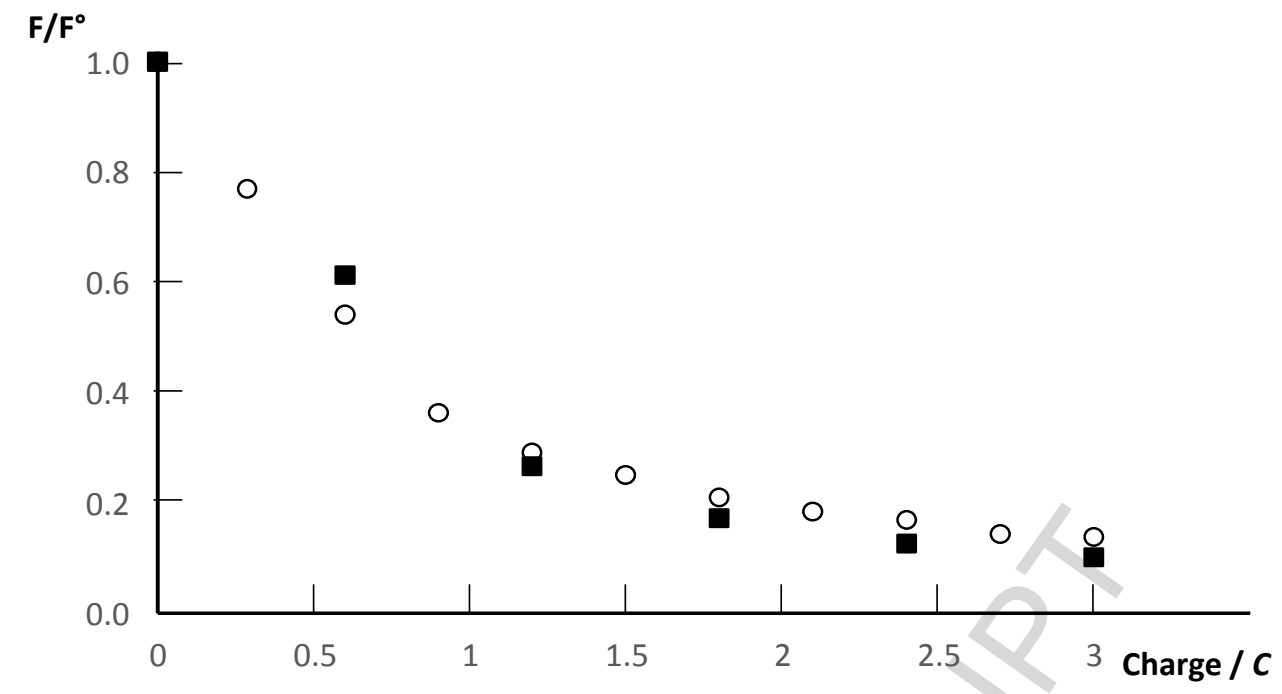

Figure 4

White circles : relative fluorescence intensity recorded as a function of the charge during the $150 \mathrm{~mA}$ galvanostatic reductive electrolysis of a $3 \mathrm{~mL}$ solution of NBD-G $\left(0.5 \mu \mathrm{mol} . \mathrm{L}^{-1}\right)$ in aqueous PBS $\left(50 \mathrm{mmol} . \mathrm{L}^{-1}\right)$ - same data as Figure 2-.

Black squares : relative fluorescence intensity recorded as a function of the charge during the $150 \mathrm{~mA}$ galvanostatic reductive electrolysis of a $3 \mathrm{~mL}$ acidified solution of NBD-G $\left(0.5 \mu \mathrm{mol} . \mathrm{L}^{-1}\right)$ in aqueous PBS (50 mmol. $\left.L^{-1}\right)+20 \mu L$ phosphoric acid at $1 M$.

As can be observed in Figure 4, the addition of a strong acid preserves the quenching capacity of the electrochemical procedure towards NBD fluorescence. The addition of a small amount of a relatively strong acid (hydrochloric or phosphoric) finally provides adequate $\mathrm{pH}$ conditions for the electrolysis without significantly affecting neither the composition of the buffer nor its osmolarity (mostly fixed by sodium chloride). We have systematically applied these optimized experimental conditions in the following experiments featuring NBD-labelled cel penetrating peptides incubated with LUVs.

3.5 Electrochemical quenching of NBD labelled CPPs in the presence of LUVS

We have implemented the electrochemical reduction procedure to quench the fluorescence of NBD-tagged CPPs previously incubated with LUVs. This methodology was aimed at providing a more reliable quenching method to estimate the proportion of peptides internalized in large unilamellar vesicles. As already underlined, NBD fluorescence is routinely quenched with dithionite $\mathrm{S}_{2} \mathrm{O}_{4}{ }^{2-}[10,18]$, a chemical reducer, which may partially and slowly penetrate in the lumen of LUVs [21] and therefore lead to underestimate 
the proportion of internalized peptides. In this context, the heterogeneous character of the reduction of NBD using electrochemical techniques should overcome this drawback. We have tested the electrochemical quenching method in the quantification of peptide internalization. We have selected three representative NBD-labelled cell penetrating peptides (R9-NBD, RW9-NBD and penetratin-NBD) and compared the results with the classical dithionite (DT) quenching procedure below the phase transition temperature $(\mathrm{Tm})$ and at $\mathrm{T}=\mathrm{Tm}\left(\mathrm{Tm}=41^{\circ} \mathrm{C}\right.$ for DPPG). Actually, the drawbacks of DT highlighted in the introduction (slow internalization in vesicles) should not interfere in this fast quenching procedure, allowing an evaluation of the electrochemical extinction method vis à vis DT quenching, used as reference (considering that fluorescence quenching is carried out at $20^{\circ} \mathrm{C}$, NBD internalization should be negligible at short timescales). The electrochemical reduction was systematically carried out at a constant current electrolysis of $150 \mathrm{~mA}$ during $20 \mathrm{~s}$, therefore engaging 3 coulombs. The percentage of fluorescence extinction obtained for each peptide after an incubation of 5 minutes in the presence of DPPG LUVs is reported in Table 1:

\section{Table 1}

Electrochemical and chemical (DT) quenching of the fluorescence of NBD-labelled peptides $(0.1 \mu \mathrm{M})$ incubated with DPPG LUVs (DPPG $10 \mu \mathrm{M}$ ) (each experiment was performed in triplicate)

\begin{tabular}{|l|c|c|c|c|}
\hline & \multicolumn{2}{|c|}{5 min incubation with LUVs at $20^{\circ} \mathrm{C}$} & \multicolumn{2}{c|}{5 min incubation with LUVs at $41^{\circ} \mathrm{C}$} \\
\hline Cationic CPP & $\begin{array}{c}\text { Electrochemical } \\
\text { extinction at } 20^{\circ} \mathrm{C}\end{array}$ & $\begin{array}{c}\text { DT extinction } \\
\text { at } 20^{\circ} \mathrm{C}\end{array}$ & $\begin{array}{c}\text { Electrochemical } \\
\text { extinction at } 20^{\circ} \mathrm{C}\end{array}$ & $\begin{array}{c}\text { DT extinction } \\
\text { at } 20^{\circ} \mathrm{C}\end{array}$ \\
\hline $\begin{array}{l}\text { NBD-R9 } \\
\text { (non } \\
\text { amphipathic) }\end{array}$ & $97 \pm 1 \%$ & $99 \pm 1 \%$ & $88 \pm 2 \%$ & $84 \pm 7 \%$ \\
\hline $\begin{array}{l}\text { NBD-RW9 } \\
\text { (secondary } \\
\text { amphipathic) }\end{array}$ & $98 \pm 2 \%$ & $99 \pm 1 \%$ & $46 \pm 7 \%$ & $32 \pm 5 \%$ \\
\hline $\begin{array}{l}\text { NBD-Pen } \\
\text { (secondary } \\
\text { amphipathic) }\end{array}$ & $97 \pm 2 \%$ & $99 \pm 1 \%$ & $70 \pm 3 \%$ & $74 \pm 5 \%$ \\
\hline
\end{tabular}

The proportion $Q$ of quenched peptides is estimated as the ratio between the fluorescence lost during incubation $\left(F^{\circ}-F\right)$ and the fluorescence at the origin of the incubation period $F^{\circ}$, i.e. $Q=\left(F^{\circ}-F\right) / F^{\circ}$. Accordingly, the percentage of extinction reported in Table 1 is defined as (1-Q)x100. The relative uncertainty of this estimation increases for incubations carried out at $41^{\circ} \mathrm{C}$ which corresponds to the fluid phase of DPPG and therefore to faster dynamics for lipid re-organization and this may explain the variability in fluorescent peptide distribution.

Table 1 shows that the electrochemical procedure at $20^{\circ} \mathrm{C}(\mathrm{T}<\mathrm{Tm}$, liquid ordered phase) gives results similar to the DT method, whatever the peptide considered. This good correlation between electrochemical- and DT-quenching discards the occurrence of LUV destabilization namely through a possible electroporation 
generated at the electrode. Even if this cannot be totally ruled out for long timescales, electroporation is unlikely or negligible in our electrolysis conditions since it would have allowed CPPs to undergo trafficking through the pores and therefore total fluorescence extinction would have been observed. At $20^{\circ} \mathrm{C}$, when the LUVs are in a liquid ordered phase, the extinction of NBD fluorescence is nearly quantitative, indicating that the peptides have not been internalized. At $41^{\circ} \mathrm{C}$, a fraction of R9-NBD was internalized (nearly 1214\%) while secondary amphipathic peptides RW9- and Pen-NBD exhibited a higher proportion of internalization, as expected and described using only DT as quencher [10].

These results show that the electrochemical extinction of NBD fluorescence affects a similar proportion of CPPs than the one quenched with DT, whatever the nature of the CPP. These observations fully validate the electrochemical procedure as a method efficient for the quenching of non-internalized NBD-labelled peptides.

\section{Conclusion}

We have developed a quantitative electrochemical methodology aimed at quenching the fluorescence of NBD-labelled peptides contained in milliliter-range samples. Once optimized, this procedure does not require expert electrochemical setup/apparatus. It appears reliable for the monitoring of peptide internalization in large unilamellar vesicles and favourably compares with the classical dithionite reductive method, since the quenching proceeds without any additional chemical agent. Accordingly, several drawbacks observed with dithionite (slow internalization in LUVs, degradation with time, reaction with $\mathrm{O}_{2}$ ) are discarded, making this electrochemical method more versatile to perform large screening assays on various peptide/phospholipid combinations and at different temperatures. Accordingly, a more reliable information on the passage of peptides across lipid membranes can be expected from the implementation of this electrochemical procedure. This methodology also opens new perspectives in the quenching of fluorescence emitted by other fluorophores and other molecules. Indeed, NBD-tagged phospholipids have been found to undergo "leaflet-specific" electrochemical reduction in Giant Unilamellar Vesicles, i.e. only the external leaflet is electroactive, as confirmed with unsymmetrical vesicles[22].

\section{Acknowledgements}

The authors warmly acknowledge Christian Amatore for his kind interest in this work and for the enriching discussions. This work was supported by the Agence Nationale de la Recherche (grant number: ANR-12BS08-0002-01 “ELIPTIC”).

\section{References}


[1] J.-M. Swiecicki, F. Thiebaut, M. Di Pisa, S. Gourdin-Bertin, J. Tailhades, C. Mansuy, F. Burlina, S. Chwetzoff, G. Trugnan, G. Chassaing, S. Lavielle, How to unveil self-quenched fluorophores and subsequently map the subcellular distribution of exogenous peptides, Scientific Reports 6 (2016).

[2] A. Eguchi, S.F. Dowdy, siRNA delivery using peptide transduction domains, Trends in Pharmacological Sciences 30(7) (2009) 341-345.

[3] B. Gupta, T.S. Levchenko, V.P. Torchilin, Intracellular delivery of large molecules and small particles by cell-penetrating proteins and peptides, Advanced Drug Delivery Reviews 57(4) (2005) 637-651.

[4] E. Koren, V.P. Torchilin, Cell-penetrating peptides: breaking through to the other side, Trends in Molecular Medicine 18(7) (2012) 385-393.

[5] V.P. Torchilin, Cell penetrating peptide-modified pharmaceutical nanocarriers for intracellular drug and gene delivery, Biopolymers 90(5) (2008) 604-610.

[6] S. Lindberg, D.M. Copolovici, U. Langel, Therapeutic delivery opportunities, obstacles and applications for cell-penetrating peptides, Therapeutic delivery 2(1) (2011) 71-82.

[7] M. Zorko, U. Langel, Cell-penetrating peptides: mechanism and kinetics of cargo delivery, Advanced Drug Delivery Reviews 57(4) (2005) 529-545.

[8] S.T. Henriques, M.N. Melo, M.A.R.B. Castanho, How to address CPP and AMP translocation? Methods to detect and quantify peptide internalization in vitro and in vivo (Review), Molecular Membrane Biology 24(3) (2007) 173-U2.

[9] I. Mager, E. Eiriksdottir, K. Langel, S.E.L. Andaloussi, U. Langel, Assessing the uptake kinetics and internalization mechanisms of cell-penetrating peptides using a quenched fluorescence assay, Biochimica Et Biophysica Acta-Biomembranes 1798(3) (2010) 338-343.

[10] J.-M. Swiecicki, M. Di Pisa, F. Burlina, P. Lecorche, C. Mansuy, G. Chassaing, S. Lavielle, Accumulation of Cell-Penetrating Peptides in Large Unilamellar Vesicles: A Straightforward Screening Assay for Investigating the Internalization Mechanism, Biopolymers (Peptide Science) 104(5) (2015) 533-543.

[11] J.N. Miller, Some recent advances in fluorescence spectroscopy, Analytical Letters 39(5) (2006) 851-862.

[12] R.A. Kenner, A.A. Aboderin, New Fluorescent Probe For Protein And Nucleoprotein Conformation - Binding Of 7-(Para-Methoxybenzylamino)-4-Nitrobenzoxadiazole To Bovine Trypsinogen And Bacterial Ribosomes, Biochemistry 10(24) (1971) 4433-\&.

[13] S. Mazeres, V. Schram, J.F. Tocanne, A. Lopez, 7-nitrobenz-2-oxa-1,3-diazole-4-yl-labeled phospholipids in lipid membranes: Differences in fluorescence behavior, Biophysical Journal 71(1) (1996) 327-335.

[14] R.S. Brown, J.D. Brennan, U.J. Krull, Self-Quenching Of Nitrobenzoxadiazole Labeled Phospholipids In Lipid-Membranes, Journal of Chemical Physics 100(8) (1994) 6019-6027.

[15] H. Funabashi, S. Ogino, M. Saito, H. Matsuoka, Utilization of Fluorescent Glucose Analog 2NBDG as a Metabolic Indicator for FACS Analysis during ES Cell Differentiation, Electrochemistry 80(5) (2012) 299-301.

[16] M. Di Pisa, G. Chassaing, J.-M. Swiecicki, Translocation Mechanism(s) of Cell-Penetrating Peptides: Biophysical Studies Using Artificial Membrane Bilayers, Biochemistry 54(2) (2015) 194207.

[17] J. Bae, M.G. Choi, J. Choi, S.-K. Chang, Colorimetric signaling of hydrogen sulfide by reduction of a phenylseleno-nitrobenzoxadiazole derivative, Dyes and Pigments 99(3) (2013) 748752.

[18] J.C. McIntyre, R.G. Sleight, Fluorescence Assay for Phospholipid Membrane Asymmetry, Biochemistry 30(51) (1991) 11819-11827.

[19] C. Angeletti, J.W. Nichols, Dithionite quenching rate measurement of the inside-outside membrane bilayer distribution of 7-nitrobenz-2-oxa-1,3-diazol-4-yl-labeled phospholipids, Biochemistry 37(43) (1998) 15114-15119. 
[20] C. Neubauer, U. Schreiber, DITHIONITE-INDUCED FLUORESCENCE QUENCHING DOES NOT REFLECT REDUCTIVE ACTIVATION IN SPINACH-CHLOROPLASTS, Botanica Acta 102(4) (1989) 314-318.

[21] M.J. Moreno, L.M.B.B. Estronca, W.L.C. Vaz, Translocation of phospholipids and dithionite permeability in liquid-ordered and liquid-disordered membranes, Biophysical Journal 91(3) (2006) 873-881.

[22] O. Buriez, E. Labbé, J. Delacotte, A.I. Perez Jimenez, L. Challier, Selective Electrochemical Bleaching of the outer Leaflet of Fluorescently Labeled Giant Liposomes, Chemistry A European Journal (Accepted) (2016) DOI : 10.1002/chem.201605786.

[23] F. Miomandre, R. Meallet-Renault, J.-J. Vachon, R.B. Pansu, P. Audebert, Fluorescence microscopy coupled to electrochemistry: A powerful tool for the controlled electrochemical switch of fluorescent molecules, Chemical Communications (16) (2008) 1913-1915.

[24] S. Mi, J. Wu, J. Liu, Z. Xu, X. Wu, G. Luo, J. Zheng, C. Xu, AIEE-Active and Electrochromic Bifunctional Polymer and a Device Composed thereof Synchronously Achieve Electrochemical Fluorescence Switching and Electrochromic Switching, Acs Applied Materials \& Interfaces 7(49) (2015) 27511-27517.

[25] S. Seo, Y. Kim, J. You, B.D. Sarwade, P.P. Wadgaonkar, S.K. Menon, A.S. More, E. Kim, Electrochemical Fluorescence Switching from a Patternable Poly(1,3,4-oxadiazole) Thin Film, Macromolecular Rapid Communications 32(8) (2011) 637-643.

[26] C.-P. Kuo, Y.-S. Lin, M.-k. Leung, Electrochemical fluorescence switching properties of conjugated polymers composed of triphenylamine, fluorene, and cyclic urea moieties, Journal of Polymer Science Part a-Polymer Chemistry 50(24) (2012) 5068-5078.

[27] I.-S. Shin, T. Hirsch, B. Ehrl, D.-H. Jang, O.S. Wolfbeis, J.-I. Hong, Efficient Fluorescence "Turn-On" Sensing of Dissolved Oxygen by Electrochemical Switching, Analytical Chemistry 84(21) (2012) 9163-9168.

[28] H. Lund, Cathodic Reduction of Nitro and related Compounds, Organic Electrochemistry - an introduction and a guide, Marcel Dekker1991, pp. 401-432.

[29] J.S. Jaworski, Aromatic Nitrogen-Containing Compounds, in: O. Hammerisch, B. Speiser (Eds.), Organic Electrochemistry Revised and Expanded, CRC Press2016, pp. 1121-1200.

[30] J.A. Squella, S. Bollo, L.J. Nunez-Vergara, Recent developments in the electrochemistry of some nitro compounds of biological significance, Current Organic Chemistry 9(6) (2005) 565-581. [31] K. Kristensen, J.R. Henriksen, T.L. Andresen, Adsorption of Cationic Peptides to Solid Surfaces of Glass and Plastic, PLoS ONE 10(5) (2015) e0122419.

[32] B.P. Chaplin, Critical review of electrochemical advanced oxidation processes for water treatment applications, Environmental Science-Processes \& Impacts 16(6) (2014) 1182-1203. [33] A.H. Waterfall, G. Singh, J.R. Fry, C.A. Marsden, The measurement of lipid peroxidation in vivo, Brain Research Protocols 2(1) (1997) 17-22. 


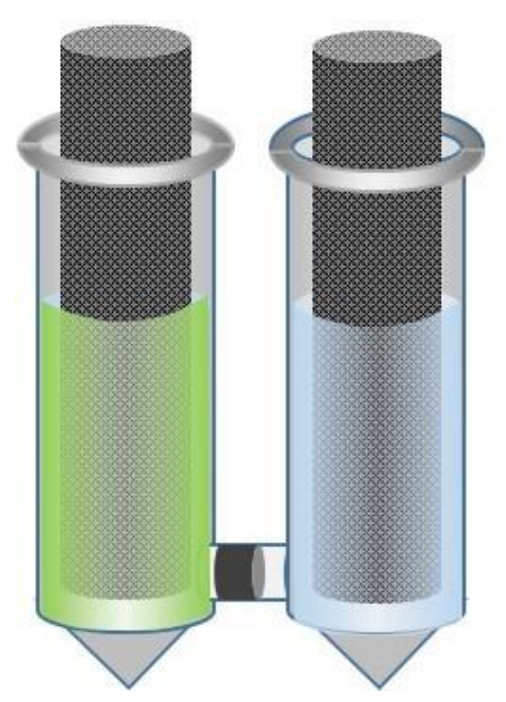

Fluorescence Electrochemical Quenching

Graphical abstract

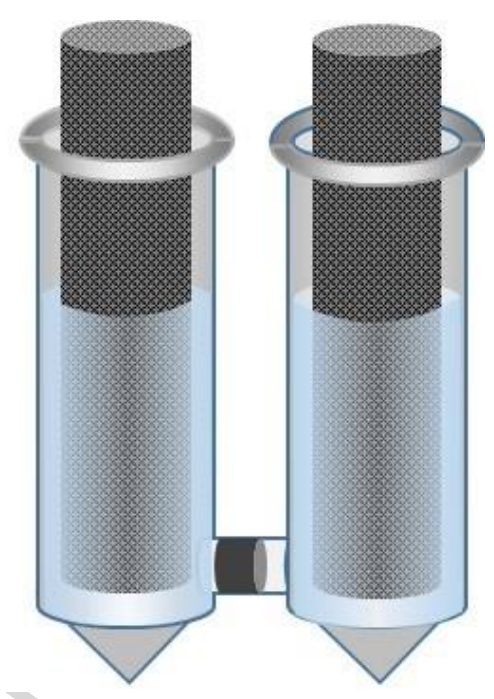




\section{Research highlights}

A quantitative electrochemical fluorescence quenching method is proposed for the study of CPP internalization into LUVs.

- The electrochemical quenching proceeds in 20s without affecting neither the buffer capacity nor the integrity of LUVs.

The method favorably compares to the classical dithionite quenching and has been validated on selected cell penetrating peptides. 